\title{
Ein Brief an Hans Albert
}

\author{
Von Günter Dlugos
}

Lieber Hans,

unser Kontakt begann mit Deiner Rezension meiner Dissertation in einer wissenschaftlichen Fachzeitschrift.

Ich bin nicht auf direktem Weg zur Wissenschaft gelangt, weil mir in der nationalsozialistischen Zeit wegen eines Tuberkuloseverdachtes der eingeschlagene Weg zum Abitur in der Obersekunda abgeschnitten wurde. Erst nachdem ich Ende 1945 aus russischer Kriegsgefangenschaft entlassen worden war, konnte ich die Vorbereitung auf das Abitur als 30-Jähriger neben dem Gelderwerb in Abendkursen nachholen. Nach dem Studium der Betriebswirtschaftslehre und Diplom folgte die Dissertation zum Thema „Kritische Analyse der ertragsgesetzlichen Kostenaussage“ deshalb erst im Jahre 1961.

Durch Deine Rezension meiner Dissertation brachtest Du mich erstmalig mit dem von Dir vertretenen modernen wissenschaftstheoretischen Denken in Berührung. Daraufhin suchte ich den Kontakt zu Dir, zu welchem mir unser gemeinsamer Freund Herbert Stachowiak verhalf.

Deine Einladung zum „Europäischen Forum Alpbach“ verschaffte mir Zugang zu einem Kreis, der mir neue wissenschaftliche Perspektiven eröffnete und aus dem wertvolle persönliche Freundschaften erwuchsen. Deine wissenschaftstheoretischen Veröffentlichungen und die vertiefenden Gespräche mit Dir wurden mir zum Fundament meines wissenschaftlichen Denkens.

Ich möchte Dir, meinem gleichaltrigen Lehrer, dafür herzlich danken!

Dein Günter, in meinem 97. Lebensjahr meiner Tochter diktiert.

Berlin, den 4. August 2017 